\title{
Thermodynamic Processes in Nanostructured Thermocoatings
}

\author{
David Bozsaky \\ Department of Architecture and Building Construction, Faculty of Architecture, Civil Engineering and \\ Transport Sciences, Széchenyi István University, H-9024 Győr, Hungary, Egyetem tér 1, \\ bozsaky@gmail.com
}

\begin{abstract}
In the 21st century, global climate change and the high level of fossil energy consumption have introduced changes affecting all sectors of the economy, including the building industry. This process has prompted EU members to create strict regulations in building energetics. It has become a serious task for architects to find more effective ways for thermal insulation. One of these options is the application of nanostructured materials. Among them nano-ceramic thermocoatings open a wide range of research fields, because complete agreement had not been already found about their insulating effect. In order to explore and describe the thermodynamic process inside nano-ceramic thermocoatings 6 series of heat transfer resistance experiments were performed in 2014-2018. Several building structure configurations with 12 different orders of layers were tested with a standard heat flow meter. On basis of these results it could be concluded that in case of nano-structured thermocoatings convective heat transfer coefficient might be taken account in different way than in case of traditional macro-structured thermal insulation materials. Based on research results, the limits of its applicability can also be concluded. It has also been found that the insulating effect of nanostructured thermocoatings depends on the material characteristics of the insulated surface.
\end{abstract}

Keywords: Thermal Insulation, Nanotechnology, Thermocoating, Thermodynamics, Building Physics.

\section{Introduction}

In the $21^{\text {st }}$ century, humanity has faced serious problems of energy and environmental aspects. Reducing energy consumption and preferring renewable materials with low environmental impact are fundamental tools in order to slow the degradation of our environment as well as early exhaustion of non-renewable fossil energy resources. Building sector represents over $40 \%$ of global energy consumption and $56.7 \%$ in carbon dioxide emissions, which is considerable (Shea et al., 2012; Anestopoulou et al., 2017). Because of these reasons regulations relating to thermal insulation performance of buildings are getting more and more rigorous nowadays. It has become a serious task for architects and civil engineers to find more and more effective ways for thermal insulation of buildings.

The appearance of nanotechnology-based thermal insulation materials in building industry opened several possibilities in the 1990s for designers because of their high-performance thermal insulating quality (Leydecker, 2008). A variety of nanotechnology-based thermal insulation materials could be found in building industry (e.g., aerogel, VIPs), from which nano-ceramic thermocoatings are generally considered to be the most critical because of the contradictory technical data about their thermal insulating mechanism that could be founded in producers' handouts and also in special literature. Therefore, this material has become the focus of this paper. 


\section{Nano-Ceramic Thermocoatings}

Synthetizing of nano-ceramic microspheres was developed in 1981 by S. Komarneni and R. Roy. This so-called 'sol-gel' process enabled researchers to test the properties of nanoceramics (Hoffman et al., 1984). To produce nano-ceramics at a more efficient way this process was later replaced by microwave sintering.

The most paint-on insulation products contain microscopic vacuum-hollow ceramic microspheres with a diameter of 20-120 $\mu \mathrm{m}$ and with a cellular wall thickness of 50-200 nm. Nano-ceramic thermocoatings are made of melted glass or ceramics on high gas-pressure and high temperature $\left(1500^{\circ} \mathrm{C}\right)$. After cooling down, the pressure ends, leaving vacuum inside the microspheres. A mixture of synthetic rubber and other polymers is used as binding materials. Its main components are styrene (20\%) and acryl latex (80\%). Styrene enhances mechanical strength and acryl latex makes nano-ceramic coating resistant against weather conditions and provides flexibility. Other additives (e.g., biocides, anti-fouling and antifungal materials) make the final product durable and mold-proofed (Thermo-Shield Inc., 2017; Lan et al., 2014).

Nano-ceramic coatings are typically used for exterior and interior wall insulation, but they are also suitable for pipe insulation and protection against fire and corrosion. They can be easily transmitted to hard-to-reach places. After mixing the ceramic microspheres with binding material, additives and water, a brush, roller or spray can be used to apply on the surface to be insulated. All surfaces must be clean and free from any contamination before

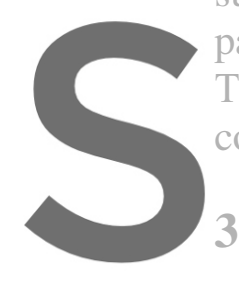
painting. Generally two insul
The drying time of a layer
complete solidification takes
3 Literature Sunmary
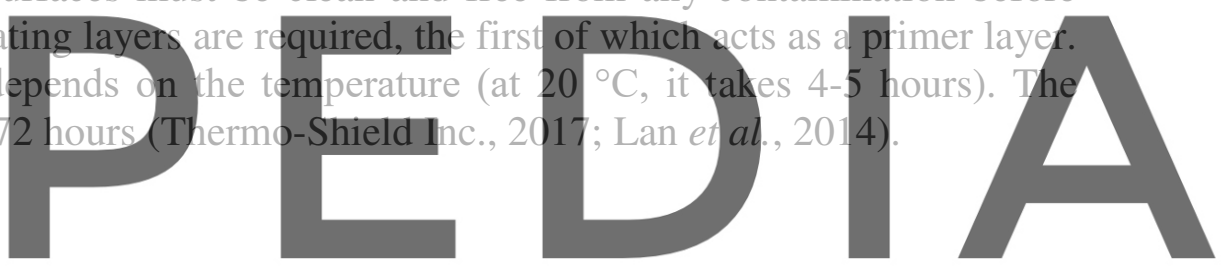

Special literature provides different data about thermal insulation quality and thermodynamic

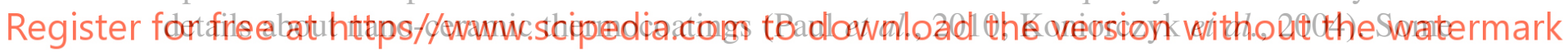
sources state that their thermal conductivity is around $0.001-0.003 \mathrm{~W} / \mathrm{mK}$ based on measurements of university laboratories in Latvia, Russia (Volgograd) and Hungary (Debrecen) (Orbán, 2012; Thermo-Shield Inc., 2017). Other sources publish much higher values (from $0.014 \mathrm{~W} / \mathrm{mK}$ to $0.140 \mathrm{~W} / \mathrm{mK}$ ) and talk about their effective thermal conductivity which contains the internal and external convective heat transfer coefficients $\left(h_{i}\right.$ and $\left.h_{e}\right)$ of the enclosed nanoscale pores inside the nanostructure. These details are often not confirmed by documented laboratory tests or refer to insufficiently introduced experiments (Orbán, 2015; Lakatos, 2016; Chukhlanov et al., 2017). Others calculate thermal conductivity of nanoceramic coatings from heat transfer coefficient (U-value) of a global building structure (Lakatos, 2016). Each method has the same problem that it tries to determine thermal conductivity by an indirect way using conventional data and calculation and it does not take in account that physical and chemical processes inside structures in range from 1 to 100 nanometers can occur differently than in traditional macro sizes.

In order to test thermal performance of nano-ceramic thermocoatings energy balance was investigated in periods of heating and also in the summer at external building surfaces using dynamic outdoor testing. Measurements demonstrated that coating consisting of hollow ceramic microspheres has the same thermodynamic properties as a standard facing coating 
(Čekon, 2013; Čekon et al., 2014). Spectral emissivity properties and reflective ability of nano-ceramic thermal insulation coatings were also tested and measured data demonstrated that coatings have the same radiant properties as standard building coatings (Čekon, 2012; Ádám et al., 2016). Based on GOST 23630.2-79 (Russian standard) using an IT- $\lambda-400$ instrument thermal conductivity of nano-ceramic coatings consisted of hollow inorganic microspheres measured to be $0.10-0.18 \mathrm{~W} / \mathrm{mK}$ and the effective thickness of the thin-film insulation coating was determined at least $5 \mathrm{~mm}$ (that requires application of 4 layers of material at each layer thickness of 1-1.5 mm) (Chukhlanov et al., 2017).

Nano-ceramic thermocoating was applied on façade walls of an experimental building and the total energy consumption of the building was examined. It has been shown that there is an effective thermal insulating effect of the coating both in winter and summer. However, exact value of conductivity was not determined (Oda et al., 2015). Similar conclusion was made after examining a $10 \mathrm{~cm}$ thick masonry wall with heat chamber method under summer climatic conditions (outside wall surface was covered with nano-ceramic thermocoating). It was found that thermal insulating ability is up to $25 \%$ more effective when the coating was applied in 2 or 3 layers (Esfandyari et al., 2018).

Other researchers claim that thermal insulation coatings can highly increase heat transfer resistance of the insulated surface by reducing convective heat transfer coefficient (Orbán, 2015). Experiments have shown that they are able to improve the heat transfer coefficient of solid brick masonry (Lakatos, 2016). It has also been found that thermal insulation capacity of nano-ceramic thermocoatings is affected by its thermal inertia (thermal lag). During the review of heat transfer processes, a further diseovery has been made that the physical equations used for atomic diffusion can be applied to heat diffusion (Lakatos, 2017).

4 Laboratory Experiments

The main research task was to clear and describe the thermphysical processes inside nanoceramic thermocoatings. Based on the literature review, it was intended to perform series of

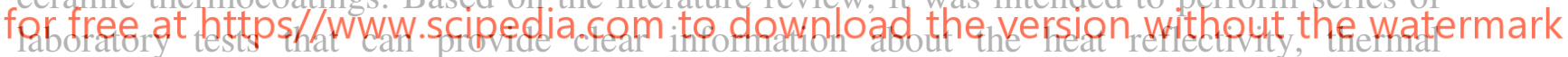

conductivity and heat transfer resistance of nano-ceramic thermocoatings. After studying the special literature six experiments were made in the Laboratory of Building Materiais and Building Physics at Széchenyi István University (Győr, Hungary) in 2014-2018.

\subsection{Experiment 1 and Experiment 2}

Experiment 1 and Experiment 2 were conducted to find out that the material really has heat reflective ability (heat mirror effect) and to check whether it has an extremely low thermal conductivity claimed by some special literature references and the manufacturer's handouts. Results of these experiments were published in 2015-2017 but in order for better understanding a brief summary is important (Bozsaky, 2015; Bozsaky, 2017).

In Experiment 1 five types (Type 1-5) of samples were made from different kind of traditional thermal insulation materials: expanded polystyrene (EPS), extruded polystyrene (XPS) and oriented strand board (OSB). Sample Type 1 was uncoated and homogeneous, other samples were sprayed with nano-ceramic thermocoating. According to EN 12667:2001 standard Taurus TCA 300 heat flow meter was used for measurements. Thermal conductivity of homogeneous samples and the effective thermal conductivity $\left(\lambda_{\text {eff }}\right)$ of inhomogeneous 
samples (Type 2-5) were compared and results seemed to show a minor negative effect of nano-ceramic coating to thermal insulation quality. Only XPS samples showed a small positive effect with an insignificant decreasing value (Bozsaky, 2015; Bozsaky, 2017).

During Experiment 2 thermal conductivity of the pure nano-ceramic coating was measured directly with a standard heat flow meter on samples with thicknesses of 25,30 and $35 \mathrm{~mm}$ (However, this material is practically not used with such thickness, because they are applied as a $0.5-2.0 \mathrm{~mm}$ thin membrane). The average thermal conductivity in air-dry condition was $0.0690 \mathrm{~W} / \mathrm{mK}$. In addition each sample was measured 3 times in order to increase measuring accuracy (standard requires only one measurement). Analyzing the results the average thermal conductivity in air-dry condition was $0.0690 \mathrm{~W} / \mathrm{mK}$ regardless of thickness. Due to the significantly increased measurement accuracy and the fact that there was no difference in thermal conductivity of samples with different thicknesses, it could be concluded that thickness has no significant effect on thermal conductivity. Therefore it could not be clearly declared that thermal conductivity of this material has the same themal conductivity if it is used as a very thin membrane (Bozsaky, 2015; Bozsaky, 2017).

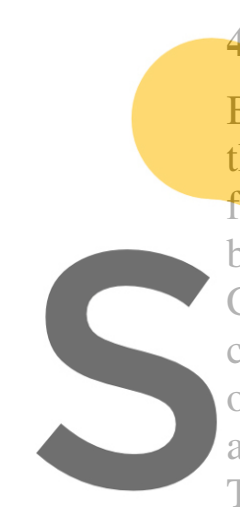

\subsection{Experiments 3-6}

Based on former experiments it was concluded that insulating effect of nano-ceramic thermocoatings is probably not caused by their extremely low thermal conductivity. As it was formerly mentioned, some sources claim that insulating effect of these materials is generated Considering it as a conducted in 2016-2018 of layers were construc an additional Air Gap There were configurations (Pioure 1 ), which cr samples as well (Type 1-6).

Register for free at https//www.scipedia.com to download the version without the watermark Table 1. Size of air gap in Experiments 3-6.

\begin{tabular}{cc}
\hline Experiment & Size of $A G(\mathrm{~cm})$ \\
\hline 3 & $10 \times 10 \times 2$ \\
& $10 \times 10 \times 3$ \\
\hline 4 & $20 \times 20 \times 2$ \\
& $20 \times 20 \times 3$ \\
\hline 5 & $20 \times 20 \times 5$ \\
\hline 6 & $20 \times 20 \times 8$ \\
\hline
\end{tabular}

Measurements were carried out by the same heat flow meter used in Experiments 1 and 2 . Effective thermal conductivity of 3-3 pieces from each type of configurations was measured using 3 different kinds of thermal insulation materials (EPS, XPS, and OSB plates). Each sample was measured 3 times. Moreover, sample Types 1-4 were measured in two ways; firstly coating was on the warm side; secondly it was on the cold side. Consequently, a total number of 883 thermal conductivity measurements were conducted. Unfortunately, because of the measuring limits (120 mm maximum sample thickness) it was possible to test only 4 Types (Types 1-4) of configurations in Experiment 6. Sample Types 5-6 were too thick (16- 
$18 \mathrm{~cm}$ ); therefore, they could not fit to the measurement chamber of the heat flow meter.

Because of the inhomogeneous, multi-layer structure heat flow meter was able to determine effective thermal conductivity $\left(\lambda_{\text {eff }}\right)$. The main focus of experiments was the difference in effective thermal conductivity between coated and uncoated samples.

All of the samples contained air gap, the effect of convection and conduction inside it was included by the $\lambda_{\text {eff }}$ value. Air gap has the same position and the same size in each sample so the conduction and convection inside air gap should be also the same in each case. This is why difference between effective thermal conductivity of coated and uncoated samples could be attributed only to the coating.
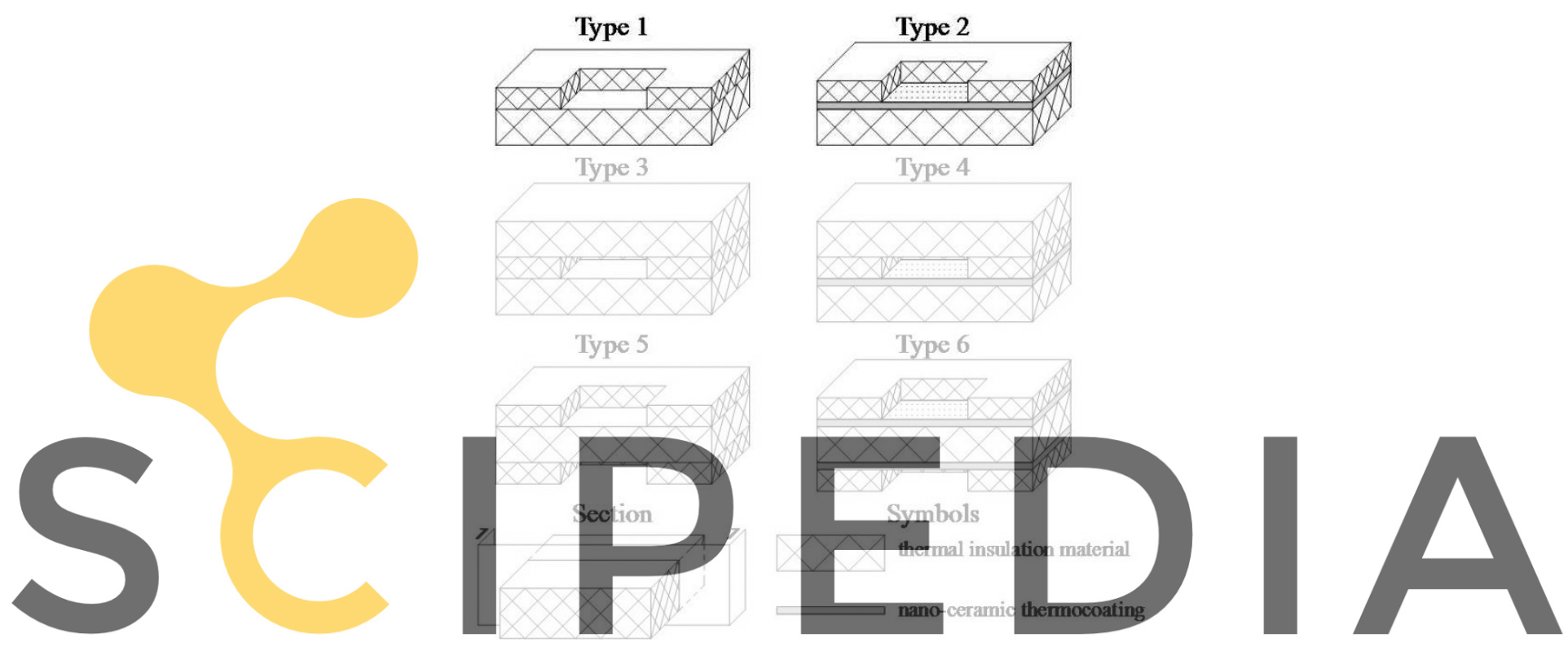

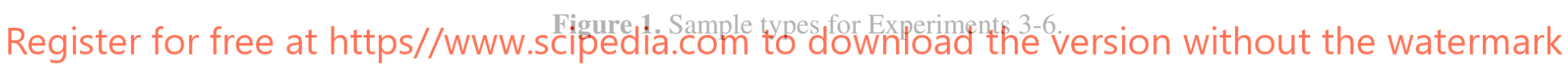

From these tests is was expected that there will be significant differences in effective thermal conductivity between coated and uncoated samples and the increasing size of air gap should cause higher changes. It was supposed that in larger air gaps air particles should have more possibility for bulk movements; thereby surface heat transfer resistance can prevail much better and higher differences may arise between coated and uncoated samples. Results were correspondent for expectations.

Unfortunately, most of the test results showed lower differences than the measurement accuracy of Taurus TCA heat flow meter $(5 \%)$. Due to the fact that measurement accuracy was increased by testing the samples in 3 times this problem was eliminated (Standard prescribes only one measurement). However; in $89 \%$ of the measurements there were no deviation between 3 test results of an individual sample and in $11 \%$ the difference was only \pm $0.0002 \mathrm{~W} / \mathrm{mK}$ which means also $0.1-0.4 \%$ accuracy instead of the theoretically $5 \%$ accuracy of the heat flow instrument. Therefore, the resulted changes in effective thermal conductivity could be considered to be relevant. 
Table 2. Changes of effective thermal conductivity in Experiments 3-6.

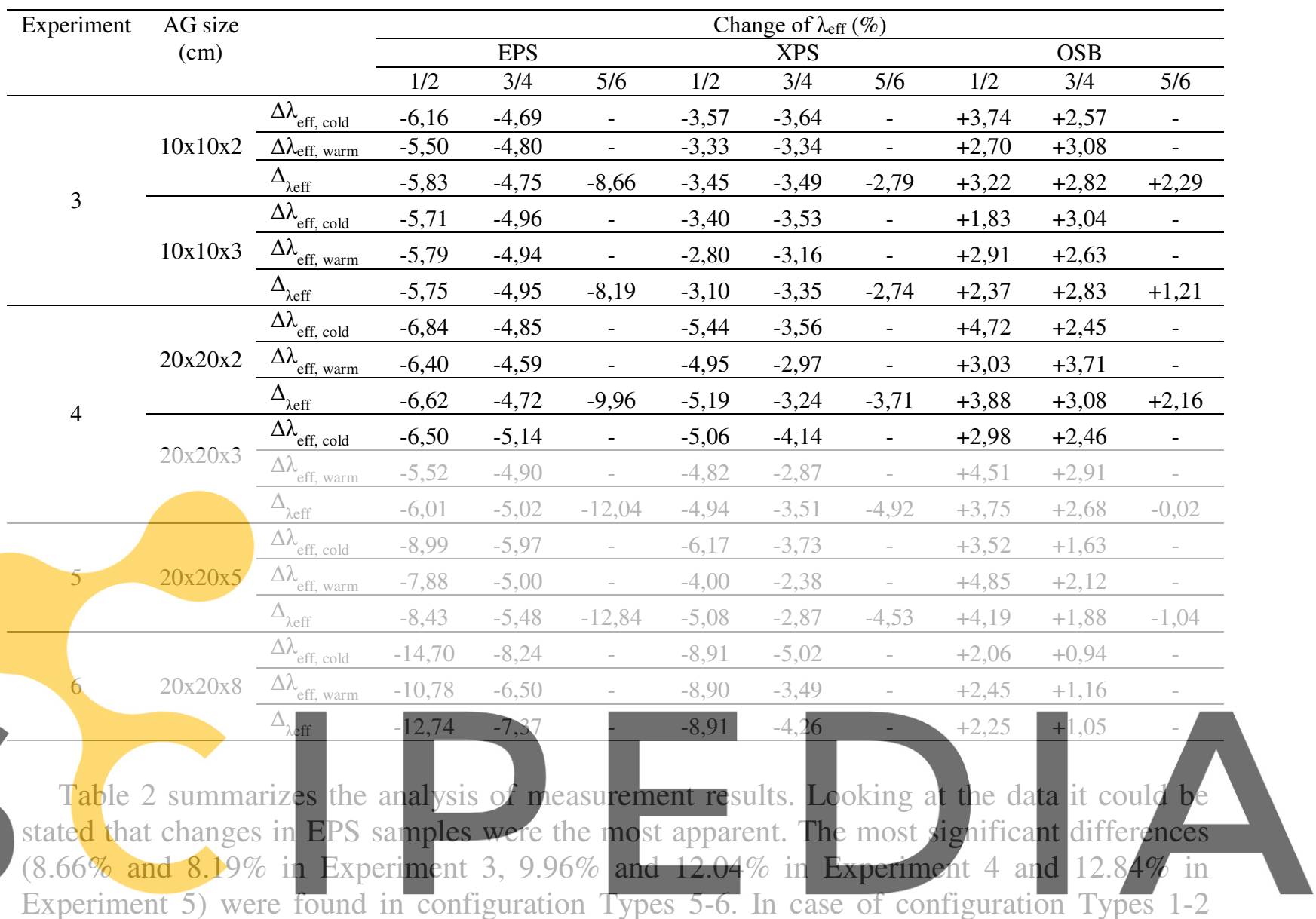
change level was also high even if the coating was on the cold or.warm. side. The lowest

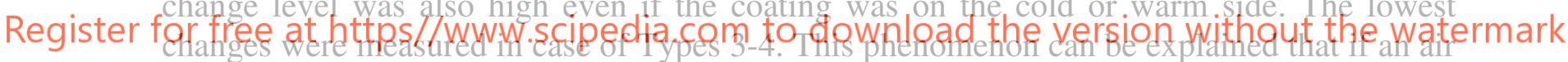

gap is closed inside two layers of thermal insulation air particles are less able to move and the effect of surface heat transfer resistance becomes smaller.

In case of XPS samples smaller changes can be observed (Table 2). Change of thermal conductivity was the most significant in configuration Types 1-2. Just like EPS samples, using the coating on the warm side the changes were lower, and the difference from samples with cold-side painting became more and more significant. In case of Types 5-6 lower changes were measured, and the lowest changes were measured in case of Types 3-4 (excepting Experiment 3). In case of XPS samples smaller changes can be observed than in case of EPS. This could be explained by the results of Experiment 1 where nano-ceramic coating itself had resulted reduction of thermal conductivity. This is why surface heat transfer resistance seems to have minor effect on thermal insulation quality

It was also a novelty that in Experiment 3 and Experiment 4 there were detectable but not enough significant differences between measurement results depending on the location of the coating (warm or cold side) in case of EPS and XPS samples. These differences became more and more significant by increasing the size of the air gap (see the results of Experiment 5 and Experiment 6 in Table 2) which showed that nano-ceramic coating has stronger effect on the 
cold side.

In case of OSB boards insulating effect of nano-ceramic coating was undetectable in Experiment 3 and 4. All measurements showed that coating has a negative effect on thermal insulation quality. Except sample Types 5-6 in Experiment 5, all measurements showed that coating has a negative effect on thermal insulation quality. It can be observed that this negative effect is decreasing by increasing the size of the air gap. In Experiment 4 nearly zero $(0.02 \%)$ change was measured and in in Experiment 5 a very small decreasing of effective thermal conductivity was detected $(-1.04 \%)$.

However, it should be noted that the negative effect of nano-ceramic thermocoating was reducing by increasing the size of the air gap. Probably, not the same material quality and composition is suitable for all building structures and materials. Every time we need to find correct solution and the same material is not suitable for all surfaces. Presumably, insulating OSB plates needs different material quality, composition or application technology than EPS and XPS plates to achieve significant insulating effect.

\section{Conclusions}

Former laboratory tests showed that nano-ceramic thermocoatings do not have an extremely low thermal conductivity that was described by the available documents of producers and distributors. Moreover, thermal conductivity of nanostructured thermocoatings is independent from materials thickness.

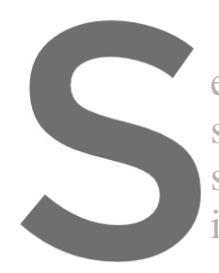

Due to the fact that

expectations, Experine special nanostructure, significantly higher su insulation materials

It can be declared that in case of using nano-structured thermocoatings on the surfaces of building structures convective heat transfer coefficient ( $h_{i}$ or $h_{e}$, according to the location of

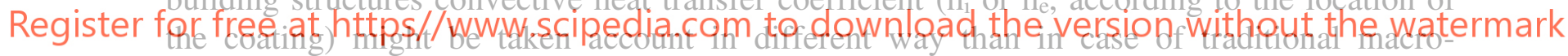
structured thermal insulation materials. New results also showed that the effectiveness of nano-ceramic thermocoatings is more intensive using them on the coid side of the structure (contrary to producers' claim that the effect is the same on warm and on cold side).

It can also be stated that the application of nano-ceramic thermocoatings between two structural layers is the least effective method from thermal insulating point of view.

Test results of OSB samples showed that the same material quality, composition and application technology may not be suitable for insulating different kind of surfaces.

Furthermore; it would be important to make in-situ heat transfer experiments with nanoceramic thermocoatings in order to understand better the thermal insulation behavior of the material. In order to achieve this goal heat transfer coefficient of several sample buildings should be measured without any thermal insulation. These basic data should be compared with the heat transfer coefficient of structures with nanostructured thermocoating.

\section{Acknowledgements}

The author would like to acknowledge and thank the financial support of the project EFOP-3.6.1-16-2016-00017 - Internationalization, initiatives to establish a new source of researchers and graduates, and development of knowledge and technological transfer as instruments of intelligent specializations at Széchenyi István University. 


\section{ORCID}

David Bozsaky: https://orcid.org/0000-0002-2099-9435

\section{References}

Ádám, L., Nagy, B. and Nemes, R. (2016). Sugárzás-visszaverő bevonatok laboratóriumi vizsgálata és fejlesztési lehetöségei (in Hungarian), Megtérülö Épületenergetika, 3(7), 35-39.

Anestopoulou, C., Efthymiou, C., Kokkonis, D. and Santamouris, M. (2017). On the development, testing and performance evaluation of energy efficient coatings for buildings, International Journal of Low-Carbon Technologies, 12(3), 310-322. doi: 10.1093/ijlct/ctw023

Bozsaky D. (2015). Laboratory test with liquid nano-ceramic thermal insulation coating, Procedia Engineering, 123, 68-75. doi: 10.1016/j.proeng.2015.10.059

Bozsaky, D. (2017). Thermodynamic Tests with Nano-Ceramic Thermal Insulation Coatings, Pollack Periodica, 12(1), 135-145. doi: 10.1556/606.2017.12.1.11

Čekon, M. (2012). Spectral emissivity properties of reflective coatings, Slovak Journal of Civil Engineering, 20(2), 1-7. doi: 10.2478/v10189-012-0007-6

Čekon, M. (2013). Thermodynamic Properties of Reflective Coatings, Advanced Materials Research, 649, 179182. doi: 10.4028/www.scientific.net/AMR.649.179

Čekon, M., Kalousek, M., Hraška, J. and Ingeli, R. (2014). Spectral optical properties and thermodynamic performance of reflective coatings in a Mild Climate Zone, Energy and Buildings, 77, 343-354. doi: 10.1016/j.enbuild.2014.04.005

Chukhlanov, V. Y., Trifonova, T. A., Selivanov, O. G., Ilina, M. E. and Chukhlanova, N.V. (2017). Thin-Film Coatings Based on Hollow Inorganic Microsheres and Polyacrilic Binder, International Journal of Applied Engineering Research, 12(7), 1194-1199. doi: 10.3311/ppci.12178

Hoffman, D., Roy R. and Komarnenis. (1984). Diphasic ceramic composites via a sol-gel method, Materials Letters, 2(3), 245-247.

Leydecker, S. (2008). Nano AG, Berlin (Germany)

Oda, T., Nakai, T., Toba, ceramic insulating paint,

Esfandyari, M., Salehi, H
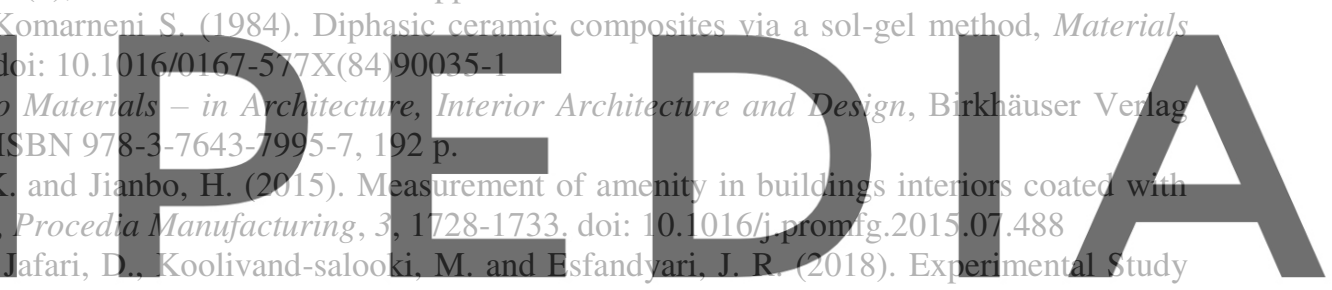
on Heat Insulation Performance of Ceramic Additives Paint (CAP) in an Indoor Closed Media, Silicon, 10

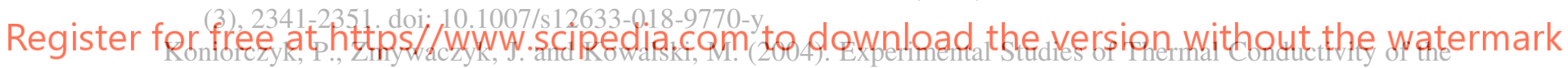
Composite Coating Consisted of Hollow Ceramic Microspheres, In Ist Scientific International Coating Congress, 4-5 November 2004, Berlin (Germany), 15 p.

Lakatos, Á. (2016). Nanotechnológiás hőszigetelő anyagok vizsgálata tömör tégla falazaton (in Hungarian), Energiagazdálkodás, 57(3-4), 21-25.

Lakatos, Á. (2017). Thermophysical Investigations of Nanotechnological Insulation Materials, AIP Conference Proceedings, 1866(1), Paper ID: 030003, 7 p. doi: 10.1063/1.4994479

Lan, W., Kexing F., Liang, Y. and Botao, W. (2014). The Application of Ceramic Coatings in Petroleum Chemical and Building Industries, In International Conference on Material and Environmental Engineering, 21-24 March 2014, Jiujiang (Jiangxi, China), Atlantis Press, pp. 146-149. doi: 10.2991/icmaee-14.2014.39

Orbán, J. (2012). A nanotechnológia építőanyagipari alkalmazásai - II. rész (in Hungarian), Magyar Épitéstechnika, 50(2-3), 54-57.

Orbán, J. (2015). Épületek energiafelhasználásának csökkentése hővédő vékonybevonattal - II. rész (in Hungarian), Magyar Építéstechnika, 53(9), 40-42.

Paul, G., Chopkar, M., Manna, I. and Das, P.K. (2010). Techniques for Measuring the Thermal Conductivity of Nanofluids - A Review, Renewable and Sustainable Energy Reviews, 14(7), 1913-1924. doi: 10.1016/j.rser.2010.03.017

Shea, A., Lawrence, M. and Walker, P (2012). Hygrothrermal performance of an experimental hemp-lime building, Construction and Building Materials, 36, 270-275. doi: 10.1016/j.conbuildmat.2012.04.123

Thermo-Shield Inc. (2017). Exterior Wall Coats, SPM Thermo-Shield Inc., Naples (Florida, United States), http://www.thermoshield.com/index.html/thermoshieldexteriorwall.html (last visited 5 May 2017) 